\title{
Promoting sunscreen use and skin self-examination to improve early detection and prevent skin cancer: quasi-experimental trial of an adolescent psycho-educational intervention
}

\author{
Gill Hubbard ${ }^{1 *}$ (D), Richard G. Kyle ${ }^{2}$, Richard D. Neal ${ }^{3}$, Vincent Marmara ${ }^{4}$, Ziyan Wang ${ }^{5}$ and Stephan U. Dombrowski ${ }^{5}$
}

\begin{abstract}
Background: Skin cancer rates are increasing. Interventions to increase adolescent sunscreen use and skin self-examination (SSE) are required.

Methods: Quasi-experimental design; 1 control and 4 intervention group schools in Scotland, UK. Participants were 15-16 year old students on the school register. The intervention was a theoretically-informed (Common-Sense Model and Health Action Process Approach) 50-min presentation, delivered by a skin cancer specialist nurse and young adult skin cancer survivor, to students in a classroom, supplemented by a home-based assignment. Outcome variables were sunscreen use intention, SSE intention/behaviour, planning, illness perceptions and skin cancer communication behaviour, measured 2 weeks pre- and 4 weeks post- intervention using self-completed pen and paper survey. School attendance records were used to record intervention up-take; students self-reported completion of the home-based assignment. Pearson's chi-square test, analysis of variance, and non-parametric Wilcoxon Signed Ranks Test were used to measure outcomes and associations between variables. Focus groups elicited students' $(n=29)$ views on the intervention. Qualitative data were analysed thematically.
\end{abstract}

Results: Five of 37 invited schools participated. 639 (81\%) students in intervention schools received the intervention; 33.8\% completed the home-based assignment. 627 (69.6\%) of students on the school register in intervention and control schools completed a questionnaire at baseline; data for 455 (72.6\%) students were available at baseline and follow-up. Focus groups identified four themes - personal experiences of skin cancer, distaste for sunscreen, relevance of SSE in adolescence, and skin cancer conversations. Statistically significant $(p<0.05)$ changes were observed for sunscreen use, SSE, planning, and talk about skin cancer in intervention schools but not the control. Significant associations were found between sunscreen use, planning and 2 illness perceptions (identity and consequence) and between SSE, planning and 3 illness perceptions (timeline, causes, control).

Conclusions: It is feasible to promote sunscreen use and SSE in the context of an adolescent school-based psychoeducation intention. Further research is required to improve study uptake, intervention adherence and effectiveness.

Trial registration: ISRCTN11141528

Keywords: Skin cancer, Skin self-examination, Adolescence

\footnotetext{
* Correspondence: gill.hubbard@uhi.ac.uk

${ }^{1}$ School of Health, Social Care and Life Sciences, Centre for Health Sciences,

University of the Highlands and Islands (UHI), Old Perth Road, Inverness IV2

$3 \mathrm{JH}$, Scotland

Full list of author information is available at the end of the article
}

(c) The Author(s). 2018 Open Access This article is distributed under the terms of the Creative Commons Attribution 4.0 International License (http://creativecommons.org/licenses/by/4.0/), which permits unrestricted use, distribution, and reproduction in any medium, provided you give appropriate credit to the original author(s) and the source, provide a link to the Creative Commons license, and indicate if changes were made. The Creative Commons Public Domain Dedication waiver (http://creativecommons.org/publicdomain/zero/1.0/) applies to the data made available in this article, unless otherwise stated. 


\section{Background}

\section{Skin cancer prevention}

The burden of skin cancer in Europe is high and increasing rapidly [1]. Skin cancer incidence has increased in the United Kingdom (UK) by 360\% since the 1970s [2], with an estimated $86 \%$ of these cases attributable to excessive sunlight exposure [3]. Sunburn is implicated in the pathogenesis of different skin cancers including squamous cell carcinoma [4], basal cell carcinoma [5], and melanoma [6]. While rare, the recent rapid increase in skin cancer incidence in adolescence is attributed to environmental (e.g., excessive sun exposure leading to sunburn) and genetic factors [7-10]. Sunburn in childhood and adolescence heightens the risk of skin cancer in adulthood [6, 11-14]. For example, one United States cohort study found that the overall lifetime risk of developing skin cancer nearly doubled $(\mathrm{OR}=1.80$ (95\% CI, 1.42-2.28) if participants experienced five blistering sunburns between the ages 15 and 20 years [14]. Sun protection strategies (e.g., sunscreen use, covering up with suitable clothing, avoiding going out in the sun) act by blocking or diminishing the contact of ultraviolet radiation (UV) with the skin, thus, avoiding DNA damage and the development of skin cancer [15]. A major concern is poor sunscreen application in this age group [16-21]. In one study, adolescents were found to deliberately use a sunscreen with a low sun protection factor and delay application of sunscreen to get a tan [20]. Hence, specific instructions on the correct application and re-application of sunscreen and use of other sun protection behaviours during adolescence are urgently needed [22]. There are other reasons why adolescents are a target group for sun safety interventions. Multiple risk behaviours - smoking, hazardous alcohol consumption, low levels of physical activity, poor diet and excessive sun exposure - cluster in adolescence [23]. Many health problems manifested in adulthood have antecedents in childhood [24-26]. Behaviours (e.g. sunbathing) and attitudes (e.g. pro-tanning) associated with skin cancer emerge in adolescence and track into adulthood [27, 28]. Adolescence therefore provides a critical window of opportunity for the primary prevention of skin cancer caused by sunburn across the life-course.

\section{Early detection of melanoma}

There is no UK guidance for how often an individual should examine their skin but there is a recognition to make an appointment with a doctor if an individual notices a change to a mole, freckle or normal patch of skin [29]. The International Skin Cancer Foundation recommends a head-to-toe self-examination every month [30]. Early detection of melanoma improves survival, diseaseand treatment-related morbidity and psychological adjustment [31, 32]. A recent systematic review of eight studies showed that shorter onset to melanoma diagnosis is associated with more favourable clinical outcomes [33]. A landmark case-control study found that skin self-examination (SSE) may decrease mortality from melanoma by $63 \%$ [34], although there is lack of sufficient evidence to know with certainty the effect of SSE on melanoma incidence and stage at presentation [35]. Nonetheless, evidence suggests that over half of all melanomas are self-detected [35-37]. Learning to conduct SSE during adolescence may increase the chances of this important health behaviour becoming habitual [38] during adulthood when skin cancer incidence is higher. One study found that self-detection is associated with knowledge of the ABCD (asymmetry, border, colour, diameter) criteria used to examine moles and performance of SSE [39]. It is concerning, therefore, that a recent UK study found that less than half of adolescents recognized 'change in the appearance of existing or new mole' as a melanoma warning sign [16] and another study found that SSE in young people is rare [40]. Moreover, few young people talk about cancer [41]; yet, advice from family and friends is a trigger to seeking professional advice about a symptom suggestive of cancer [42].

\section{Behaviour change interventions}

Interventions that simultaneously promote sunscreen use to prevent skin cancer and SSE to improve early detection may be effective. A recent mobile phone text messaging intervention, targeting either sun protection or SSE in a population aged 18 to 42 years at high risk of skin cancer, found that the SSE group improved their sun protection behaviours to a similar degree as that observed in the sun protection group [43]. It concluded that repeated messages about early detection of skin cancers and encouragement to conduct SSE prompt people to consider skin cancer risk more broadly.

A review of educational interventions published in 2004 concluded that simply raising awareness of the risks of UV radiation may go some way towards improving sun protection behaviours during adolescence but is unlikely to directly translate into sustained behaviour change on its own [44]. More recent studies have therefore focused on a range of behavioural determinants, acknowledging that individuals must be motivated to perform specific behaviours (e.g., sunscreen use and SSE) and motivation must be directly translated into actual behaviours [45].

Risk perceptions are social cognitions identified by many behavioural theories as primary motivators of a range of health behaviours [46]. Recent meta-analytic evidence suggests that interventions that successfully engage and change risk perceptions produce subsequent improvements in health behaviours [47]. This proposition is supported by empirical evidence of associations 
between risk perceptions and sun protection behaviours in adolescents [18, 21, 48, 49] and SSE in adults [50,51]. Illness representations are another class of social cognitions that determine health behaviours and refer to an individual's beliefs and expectations about an illness $[52,53]$. Illness representations are central to the Common-Sense Model of illness representation and self-regulation (CSM); a study in young adults found that CSM dimensions identity (e.g., 'I have white or pale skin'), cause (e.g., 'Lots of sun exposure to skin without using sunscreen') and timeline (e.g., 'People of my age are likely to develop skin cancer') were associated with higher SSE intentions [54]. Expanded versions of CSM such as the Cognitive-Social Health Information Processing (C-SHIP) model include risk perceptions [55]. Illness perceptions (the term we use that includes risk perceptions and illness representations) are multi-dimensional and in the context of this study include adolescents' beliefs about the causes of skin cancer and their perceived ability, confidence and relevance to control for skin cancer risk at their age.

According to the Health Action Process Approach [45], behavioural intentions are more likely to be translated into action when people generate specific plans [56]. In the context of sunscreen use, empirical evidence suggests that adolescent frequent sunscreen users are more likely to use action plans related to sunscreen use (e.g., by planning to take sunscreen with them to use when at the pool or beach, during sports and when engaging in outdoor activities) compared to infrequent sunscreen users [18]. Indeed, the study found that use of action plans was the strongest predictor of sunscreen use [18].

\section{Study aims}

The intervention being tested in this feasibility study was designed to improve sun protection behaviours to prevent skin cancer and SSE to improve early detection of skin cancer. This feasibility study was for preparation of a future effectiveness trial of an intervention to increase sunscreen use and SSE during adolescence and received ethical approval from the University of Stirling Research and Ethics committee (SREC 15/16 - Paper No.66 - Version 2). The following trial parameters were measured to assess the feasibility of trial procedures: number of schools agreeing to participate, adolescent consent rate, and intervention adherence and acceptability. We hypothesised that we would observe at baseline associations between: a) sunscreen use intention and sunscreen use planning; b) SSE behaviour and SSE planning; c) SSE intention and SSE planning; d) SSE behaviour and illness perceptions; e) SSE intention and illness perceptions; f) sunscreen use intention and illness perceptions. A further purpose was to determine if a psycho-educational intervention ('Do you know your skin?') worked as intended and that we would observe the following changes in outcomes from baseline to follow-up in adolescents': i) sunscreen use intention and sunscreen use planning; ii) SSE behaviour, SSE intention and SSE planning; iii) skin cancer perceptions; and iv) talk about skin cancer in intervention group schools but not the control group schools.

\section{Methods \\ Design}

The feasibility study used a quasi-experimental design, with four schools allocated by the research team to an intervention group one to a control group, to find out if the intervention worked as intended and examine trial procedures. This was not a full randomised controlled trial; the study is not powered to measure effectiveness and there was no aim to recruit a representative sample.

\section{Study population and recruitment}

The criteria for inclusion in the study were: males and females aged 15-16 years of age. Participants were recruited from five secondary schools in Scotland. Four schools were allocated to the intervention group and one to a control group (which received the intervention after the study). A letter was sent to 35 state and independent secondary school head teachers in one city in Scotland inviting participation, which was followed up by telephone and/or email to arrange a face-to-face meeting to discuss the study and obtain agreement for the school's participation. Due to poor response, two schools in a different area in Scotland, that were already known to the research team through previous work, were invited to participate.

Once a school had consented to participate, the named parent/carer on the school register was sent a study information pack, which included a form to be returned to the school if they wished to opt their child out of the study. The parent/carer was given the opportunity to contact the research team to discuss the study by telephone or email. Students who were not opted out by a parent/carer were given their study information sheet and consent form in the classroom. Students who had been opted out of the study were given education assignments to do while their classmates completed the questionnaires.

\section{Intervention description}

The intervention was developed by the research team with the support of an expert working group that included two people who had been treated for skin cancer, three experts in health behaviour change, one policy-maker in cancer early detection, one skin cancer specialist nurse and one dermatologist. The intervention 
had two parts: a presentation delivered to students in school and a home-based assignment.

A practicing skin cancer nurse specialist delivered a 50-min presentation to students about skin cancer and SSE. Each presentation was delivered by the nurse on one occasion during the school day in a classroom. After playing a 5-min video 'Dear 16-year-old me' (http:// dcmf.ca), the nurse delivered the presentation with the aid of Microsoft PowerPoint slides and covered: personal experiences of skin cancer, incidence patterns, risk factors, associations between disease staging and survival, and benefits of SSE. A young adult skin cancer survivor gave a brief 5-min talk after the nurse-delivered presentation. The talk was about his personal experience of melanoma diagnosis at 16 years old, impacts on his life and his views on sunscreen use and SSE behaviour.

A home-based assignment comprised a booklet with instructions. Adolescents were given an exercise to self-examine their skin and asked to complete an action plan for regular monthly sunscreen use and an action plan for SSE. The SSE component of the booklet had three sections: a) information on the importance of planning; b) instructions of what should be included in the plan; c) formulating 'if-then' action plans (e.g., If I am having a shower then I will check my skin) and coping plans (e.g. To make sure I don't forget, I will add the appointment to my calendar and put a reminder post-it on the fridge).

The school allocated to the control group, received the same intervention after the study had ended.

\section{Intervention adherence and acceptability}

We assessed intervention adherence and acceptability both objectively and via self-report. Intervention adherence was defined in two ways: proportion of eligible adolescents on a school register receiving the presentation, and number of participating adolescents completing the home-based assignment. The number of adolescents in intervention schools who received the presentation was objectively measured using school attendance records. The number of adolescents doing the home-based assignment was self-reported at follow- up.

Focus groups were conducted in intervention group schools to explore adolescents' opinions about relevance, content, format and delivery methods. Focus groups $(n=3 ; 1$ intervention group school was unavailable due to exam revision timetabling) to elicit adolescents' views on the intervention's relevance, content, format and delivery methods were conducted approximately 8 weeks after the intervention. Focus groups were audio-recorded and took place during school time, in a classroom, at a time and place selected by the teacher and lasted approximately $50 \mathrm{~min}$. Confidentiality was explained and informed consent was obtained in writing.

\section{Variables and measures}

Outcome variables were measured 2 weeks before (baseline) and 4 weeks after (follow-up) the intervention in intervention schools using self-completed pen and paper survey. Teachers administered the questionnaires in the classroom. Parallel time-points were used in the control school. Only students who had consented to participate in the study completed questionnaires at these time-points. We adapted items from action and coping planning scales [57] to measure sunscreen planning and SSE planning. Items to measure illness perception were adapted from a study about SSE in young adults [54], that in turn had used items used in the Illness Perception Questionnaire [58].

\section{Sunscreen use intention}

Sunscreen use intention was measured using one item: 'Do you intend to use a high factor sunscreen if you are going out in the sun?' A five-point continuous rating scale was used to gauge response from 1 (definitely will not) to 5 (definitely will). We did not measure sunscreen use behaviour because the feasibility study was conducted in winter (January - March) and not during the summer months when sunscreen use would be highly relevant in Scotland.

\section{Sunscreen use planning}

Sunscreen use planning was measured using five items: 'I have made a detailed plan on... i) What sunscreen I will use; ii) When I will use it; iii) Where I will get it from; iv) How I will remember to carry it'; and, iv) What to do if I am tempted not to use it.' A five-point continuous rating scale was used to gauge response from 1 (completely disagree) to 5 (completely agree).

\section{SSE behaviour and intention}

SSE behaviour was measured using one item: 'In the past month, have you examined your skin for signs of possible skin cancer?' Responses were yes, no or don't know. SSE intention was measured using one item: 'Do you intend to examine your skin for signs of possible skin cancer on a regular basis.' A five-point continuous rating scale was used to gauge response from 1 (definitely will not) to 5 (definitely will).

\section{SSE planning}

SSE planning was measured using four items: 'I have made a detailed plan regarding... i) When to examine my skin for signs of possible skin cancer; ii) Where to examine my skin for signs of possible skin cancer; iii) How to examine my skin for signs of possible skin cancer'; and, iv) 'I have made a plan for dealing with things that could stop me from examining my skin for signs of possible skin cancer.' A five-point continuous rating 
scale was used to gauge response from 1 (completely disagree) to 5 (completely agree).

\section{Talking about skin cancer}

Talking about skin cancer was measured using one item: 'Have you spoken to anyone about skin cancer in the last month?' Responses were yes or no.

\section{Illness perceptions}

Five dimensions of the CSM were measured using the following items:

Identity: 'How much would getting skin cancer affect your life?' An eleven-point continuous rating scale was used to gauge response from 0 (not at all) to 10

(it would severely affect my life);

Control: 'How much control do you feel you have to prevent yourself from getting skin cancer? An eleven-point continuous rating scale was used to gauge response from 0 (not at all relevant) to 10 (very relevant).

Timeline: 'Given your age, how relevant is it to regularly examine your skin for signs of possible skin cancer?' An eleven-point continuous rating scale was used to gauge response from 0 (not at all relevant) to 10 (very relevant).

Consequence: 'How painful do you think the effects of treatments for skin cancer would be? An eleven-point continuous rating scale was used to gauge response from 0 (not at all painful) to 10 (extremely painful).

The following open-ended question was used to measure the CSM dimension cause: 'Please list in rank-order the three most important factors that you believe cause skin cancer.

\section{Social-demographic characteristics}

Socio-demographic questions were included to gather data on sex and ethnicity. Using UK government statistical service guidance [59], students were asked to choose from a list of 5 categories (White, Mixed, Asian or Asian British, Black or black British, Chinese/other) which best describes their ethnic group.

\section{Analyses}

Quantitative data analysis was conducted in three steps. First, descriptive statistics were calculated for sociodemographic variables (i.e., age, gender) and outcome variables (e.g., sunscreen use intention and planning, SSE intention, behaviour and planning, skin cancer illness perceptions, and talking about cancer) at baseline and reported as n (\%) for categorical data and mean (Standard Deviation [SD]) for continuous data. As described above, one illness perception dimension - causes - was measured using an open-ended question. We drew on the widely cited Dahlgren and Whitehead's [60] rainbow model of the main determinants of health as a framework to help identify the broad range of factors that adolescents' perceived to cause skin cancer. The open answers were categorised into, 1) age, sex and constitutional factors (e.g., age; genetics; moles; skin type; random mutation; family history; hereditary), 2) individual lifestyle factors (e.g. diet; lack of sun protection; lack of skin examination; sunburn; lack of skincare; sunbeds; tanning beds; lack of hygiene; tattoos), and 3) general environmental conditions (e.g. sun; sun exposure; radiation; UV light; pollution; heat). Second, Pearson's chi-square test was used to assess associations between sunscreen use intention/SSE intention and behaviour, and planning behaviour at baseline. Analysis of Variance (ANOVA) was used to assess associations between SSE behaviour, intention and each of the 5 CSM dimensions at baseline. Third, to assess change in outcome measures between baseline and follow-up the non-parametric Wilcoxon Signed Ranks Test was used because data were not normally distributed. The test for significance was a within-group comparison (e.g. difference between baseline and follow-up scores within intervention group schools). The study was not designed or powered to definitively measure effectiveness. However, to assess the potential influence of confounders on results sensitivity analyses were conducted. There was no statistically significant difference between the intervention and control groups in terms of gender or having a close family member with cancer, but there was a statistically significant difference of 1.2 years in the mean age of the two groups. Repeated measures ANCOVA and logistic regression were used to adjust for age in outcome analyses. Data were analysed using SPSS Statistics v21 (IBM Corporation, Armonk, NY). Significance tests were two-sided; $p<0.05$ was considered statistically significant.

Audio-recorded qualitative data from focus groups were transcribed verbatim and analysed thematically using the Framework approach [61]. Qualitative findings provided contextual and explanatory understandings of adolescents' experiences of the intervention.

\section{Results \\ Sample characteristics}

No parent/carer opted their child out from the study and no student declined to participate in the study. According to school records, there were 901 eligible students. 627 (69.6\%) completed a questionnaire at baseline. Student absence from school during examination revision period explains why we did not achieve a $100 \%$ response rate. A CONSORT pilot and feasibility flowchart is available in a Additional file 1.

The sample included 627 (female: $45.1 \%, n=283$ ) adolescents with a mean age of 16.1 years $(\mathrm{SD}=0.874)$; 
88.0\% ( $n=552)$ were 'White' ethnic background; $10.7 \%$ $(n=67)$ of adolescents had a close family member who had skin cancer. Complete data were available for 79 (61\%) and $376(48 \%)$ adolescents in the control and intervention schools respectively (i.e., we could pair baseline and follow-up for 455 students for analysis of change in outcome measures).

\section{Intervention adherence}

Eighty-three percent $(n=639)$ of adolescents in four intervention group schools $(n=771)$ received the presentation $(85 \% n=150 ; 75 \% n=60 ; 78 \% n=132 ; 87 \% n=$ 297 in each school respectively). This is higher than the total number of students in all five schools completing baseline and/or follow-up questionnaires and indicative of the difference in student absence from school on days when the intervention was delivered and questionnaires administered in schools. $33.8 \%(n=148)$ of adolescents in intervention schools reported that they did the home-based assignment to conduct skin self-examination; 65.5\% $(n=287)$ reported that they did not do the home-based assignment.

\section{Intervention acceptability}

Focus group interviews in three intervention schools with 29 students (6,10 and 13 participants in each school, respectively) were conducted. It was not feasible to conduct a focus group in one intervention school due to timetabling constraints during the period when students were preparing for exams. The following key themes were identified - personal experiences of skin cancer, distaste for sunscreen, relevance of SSE in adolescence and skin cancer conversations. Quotations to illustrate each theme are presented in a Additional file 2.

Two components of the presentation focused on personal experiences of cancer: the 'Dear 16 year old me' film that was shown at the beginning of the presentation and the brief talk from the young adult skin cancer survivor at the very end of the presentation delivered by the skin cancer specialist nurse. Adolescents could recall these personal stories because they were 'real', 'emotional' and they could 'relate'. Many adolescents said that the talk given by the young adult cancer survivor was the best feature of the presentation. Nonetheless, some adolescents found the 'Dear 16 year old me' film too contrived and 'patronising' because it was trying to be too 'cool' and 'down with the kids'. Adolescents could recall a key presentation message i.e., sunburn increases the risk of skin cancer. Nonetheless, many adolescents expressed distaste for sunscreen because of its smell and texture (e.g. thickness, greasiness) and put them off using it. Thus, while the intervention appeared to improve awareness about the health risks of excessive sun exposure, this may not be sufficient to increase sunscreen use. Adolescents could recall a key presentation message i.e., to regularly conduct SSE. Some adolescents reported that they very quickly examined their skin after the presentation. Some adolescents did not do the home-based assignment because in contrast to other homework tasks, there was no date when it had to be completed by. Nonetheless, even were the home-based assignment made compulsory, SSE is unlikely to be sustained. This is because adolescents questioned the relevance of SSE in adolescence. They understood from the presentation that skin cancer prevalence was higher in adulthood and therefore did not see the relevance of conducting SSE during adolescence. Making SSE habitual by starting the behaviour during adolescence may therefore prove difficult to instigate. Some adolescents reported that they mentioned very briefly to a parent/ carer about the presentation that they had about skin cancer. Others gave the impression that when they mentioned the presentation it provided the parent with an opportunity to reinforce key messages about sun protection. Some adolescents reported that their parent/carer looked at the home-based assignment booklet or they spoke about skin cancer with a parent/carer following the presentation. This suggests that school-delivered interventions with a home-based assignment component may reach a wider audience (e.g., parents/carers) than the direct target group (e.g., adolescents).

\section{Baseline associations}

\section{Sunscreen use intention, planning and risk perceptions}

At baseline, 30.9\% $(n=191)$ of adolescents definitely intended to use a high factor sunscreen if they were going out in the sun, and 5.3\% $(n=33)$ definitely did not intend to use a high factor sunscreen (Table 1). The difference between male and female intentions were statistically significant; more females definitely intended to use sunscreen than males $(37.5 \%(n=105)$ versus $25.4 \%$ $(n=86), p<0.001)$ (Table 1).

$14 \%(n=87)$ of adolescents had made a detailed plan When to use sunscreen; $10.8 \%(n=67)$ What sunscreen to use; $16.7 \%(n=104)$ Where to get sunscreen from; $8.8 \%(n=55)$ How to get sunscreen $(23.8 \%, n=148)$; and $8.7 \%(n=54)$ had made a Coping plan for what to do if they were tempted not to use sunscreen (Table 2).

Adolescents who intended to use sunscreen had statistically significantly higher sunscreen planning behaviour for each of the five aspects of planning: When $(p<0.001)$; What $(p<0.001)$; Where $(p<0.001)$; How $(p=0.001)$; Coping $(p=0.001)$ (Table 3$)$. For example, $86.2 \%(n=150)$ of adolescents who intended to use sunscreen had made a plan When to use sunscreen compared to $40.5 \%(n=121)$ who did not intend to use sunscreen (Table 3). 
Table 1 Sunscreen Use and Skin Self Examination (SSE) intention at baseline by gender

\begin{tabular}{|c|c|c|c|c|c|c|c|c|}
\hline \multirow[b]{2}{*}{ Intention } & & \multicolumn{2}{|l|}{ Total } & \multicolumn{2}{|l|}{ Male } & \multicolumn{2}{|c|}{ Female } & \multirow[b]{2}{*}{ Sig. } \\
\hline & & $\%$ & $n$ & $\%$ & $n$ & $\%$ & $n$ & \\
\hline \multirow[t]{5}{*}{ Sunscreen Use } & 1 - Definitely will not & 5.3 & (33) & 6.8 & (23) & 3.6 & (10) & $0.001^{* *}$ \\
\hline & 2 & 11.0 & (68) & 14.2 & (48) & 7.1 & (20) & \\
\hline & 3 & 25.2 & (156) & 26.8 & (91) & 23.2 & (65) & \\
\hline & 4 & 27.6 & (171) & 26.8 & (96) & 28.6 & (80) & \\
\hline & 5 - Definitely will & 30.9 & (191) & 25.4 & (86) & 37.5 & (105) & $p<0.001^{* * *}$ \\
\hline \multirow[t]{5}{*}{ SSE } & 1 - Definitely will not & 13.3 & (83) & 17 & (58) & 8.8 & (25) & $0.041^{*}$ \\
\hline & 2 & 29.5 & (184) & 29.3 & (100) & 29.7 & (84) & \\
\hline & 3 & 41.8 & (261) & 38.4 & (131) & 45.9 & (130) & \\
\hline & 4 & 10.7 & $(67)$ & 10.9 & (37) & 10.6 & (67) & \\
\hline & 5 - Definitely will & 4.6 & (29) & 4.4 & (15) & 4.9 & (14) & \\
\hline $\begin{array}{l}\text { Have you spoken to anyone about skin } \\
\text { cancer in the last month? }\end{array}$ & $\begin{array}{l}\text { Yes } \\
\text { No }\end{array}$ & $\begin{array}{l}9.2 \\
90.8\end{array}$ & $\begin{array}{l}(57) \\
(563)\end{array}$ & $\begin{array}{l}8.2 \\
91.8\end{array}$ & $\begin{array}{l}(28) \\
(312)\end{array}$ & $\begin{array}{l}10.4 \\
89.6\end{array}$ & $\begin{array}{l}(29) \\
(251)\end{array}$ & 0.363 \\
\hline
\end{tabular}

Note: ${ }^{*} p<0.05,{ }^{* *} p<0.01,{ }^{* * *} p<0.001$

There were statistically significant associations between sunscreen use intention and CSM dimensions identity and consequences. Adolescents who intended to use sunscreen believed more strongly that skin cancer would affect their life compared to those who did not intend to use sunscreen (mean 8.33 versus $7.67, p<0.001$ ); adolescents who believed more strongly that skin cancer would be painful compared to those who did not intend to use sunscreen (mean 7.26 versus 6.53, $p=0.002$ ). No statistically significant differences in sunscreen use intentions were observed for the CSM dimensions control, timeline (Table 4) and causes (Table 5).

\section{SSE behaviour, intention, planning and risk perceptions}

At baseline, 6.1\% $(n=38)$ of adolescents reported that they had examined their skin for signs of possible cancer in the past month and $90.1 \%(n=563)$ had not (Table 5).
No statistically significant gender differences were observed (Table 6).

4.6\% $(n=29)$ of adolescents definitely intended to conduct SSE on a regular basis and 13.3\% $(n=83)$ definitely did not intend to conduct SSE on a regular basis (Table 1). The difference between male and female intentions were statistically significant; more males definitely did not intend to conduct SSE than females $(17 \%(n=58)$ versus $8.8 \%(n=25), p=0.041)$ (Table 1).

$1.1 \%(n=7)$ of adolescents had made a detailed plan When to conduct SSE; $1.3 \%(\mathrm{n}=8)$ Where to conduct SSE; $1.3 \%(n=8)$ How to conduct SSE; and $0.8 \%(n=5)$ had made a Coping plan for dealing with things that could stop them from conducting SSE (Table 2).

Adolescents who had conducted SSE in the past month or intended to conduct SSE on a regular basis had statistically significantly higher SSE planning

Table 2 Sunscreen Use and Skin Self Examination (SSE) planning behaviour at baseline

\begin{tabular}{|c|c|c|c|c|c|c|c|c|c|c|c|}
\hline & & \multicolumn{10}{|c|}{ Planning behaviour } \\
\hline & & \multicolumn{2}{|c|}{ When } & \multicolumn{2}{|c|}{ What } & \multicolumn{2}{|l|}{ Where } & \multicolumn{2}{|l|}{ How } & \multicolumn{2}{|l|}{ Coping } \\
\hline \multicolumn{2}{|l|}{ Health Behaviour } & $\%$ & (n) & $\%$ & $(n)$ & $\%$ & $(n)$ & $\%$ & (n) & $\%$ & (n) \\
\hline \multirow[t]{5}{*}{ Sunscreen Use } & 1 - Completely disagree & 23.3 & (145) & 28.5 & (177) & 30.5 & (190) & 34.6 & (215) & 39.8 & $(247)$ \\
\hline & 2 & 15 & (93) & 19.8 & (123) & 18.8 & $(117)$ & 20.7 & (129) & 19.8 & $(123)$ \\
\hline & 3 & 23.5 & $(146)$ & 23.8 & (148) & 17.4 & (108) & 20.9 & (130) & 19.8 & $(123)$ \\
\hline & 4 & 24.3 & $(151)$ & 17.2 & $(107)$ & 16.6 & (103) & 15.0 & (93) & 11.8 & $(73)$ \\
\hline & 5 - Completely agree & 14.0 & (87) & 10.8 & (67) & 16.7 & (104) & 8.8 & (55) & 8.7 & $(54)$ \\
\hline \multirow[t]{5}{*}{ Skin Self Examination } & 1 - Completely disagree & 68.8 & $(431)$ & - & - & 64.8 & (403) & 65.1 & $(404)$ & 63.3 & (395) \\
\hline & 2 & 19.5 & (122) & - & - & 19.1 & (119) & 20.8 & (129) & 20.4 & $(127)$ \\
\hline & 3 & 8.6 & (54) & - & - & 10 & (62) & 10.3 & (64) & 13.1 & $(82)$ \\
\hline & 4 & 1.9 & (12) & - & - & 4.8 & (30) & 2.6 & (16) & 2.4 & $(15)$ \\
\hline & 5 - Completely agree & 1.1 & (7) & - & - & 1.3 & (8) & 1.3 & (8) & 0.8 & (5) \\
\hline
\end{tabular}


Table 3 Associations between sunscreen use and SSE and planning behaviour at baseline

\begin{tabular}{|c|c|c|c|c|c|c|c|c|c|c|}
\hline \multirow[b]{3}{*}{ Intention/behaviour } & \multicolumn{10}{|c|}{ Planning Behaviour (\% Yes) } \\
\hline & \multicolumn{2}{|l|}{ When } & \multicolumn{2}{|l|}{ What } & \multicolumn{2}{|l|}{ Where } & \multicolumn{2}{|l|}{ How } & \multicolumn{2}{|l|}{ Coping } \\
\hline & $\%$ & $(n)$ & $\%$ & $(n)$ & $\%$ & $(n)$ & $\%$ & $(n)$ & $\%$ & $(n)$ \\
\hline \multicolumn{11}{|c|}{ Sunscreen Use Intention } \\
\hline Yes & 86.2 & (150) & 79.8 & (190) & 75.4 & (156) & 81.1 & (120) & 82.7 & $(105)$ \\
\hline Don't know & 62.2 & $(92)$ & 54.8 & $(80)$ & 61.1 & (66) & 66.9 & $(87)$ & 68.3 & (84) \\
\hline No & 40.5 & (121) & 39.2 & (93) & 46.1 & $(141)$ & 45.5 & (156) & 46.9 & (173) \\
\hline Sig. & $<0.001$ & & $<0.001$ & & $<0.001$ & & 0.001 & & 0.001 & \\
\hline \multicolumn{11}{|l|}{ SSE Intention } \\
\hline Yes & 9.4 & (9) & - & - & 11.6 & (11) & 11.7 & $(11)$ & 9.4 & (9) \\
\hline Don't know & 3.5 & (9) & - & - & 7.0 & (18) & 4.3 & $(11)$ & 0.8 & (2) \\
\hline No & 0.4 & (1) & - & - & 3.4 & (9) & 0.4 & $(1)$ & 3.5 & (9) \\
\hline Sig. & $<0.001$ & & - & - & $<0.001$ & & $<0.001$ & & $<0.001$ & \\
\hline \multicolumn{11}{|l|}{ SSE behaviour } \\
\hline Yes & 10.5 & (4) & - & - & 16.2 & (6) & 22.2 & (8) & 13.2 & (5) \\
\hline Don't know & 20.8 & (5) & - & - & 20.8 & (5) & 16.7 & (4) & 8.3 & (2) \\
\hline No & 1.8 & $(10)$ & - & - & 4.8 & (27) & 2.1 & $(12)$ & 2.3 & (13) \\
\hline Sig. & $<0.001$ & & - & - & $<0.001$ & & $<0.001$ & & 0.001 & \\
\hline
\end{tabular}

Table 4 Associations between SSE behaviour, intention and CSM attributes at baseline

\begin{tabular}{|c|c|c|c|c|c|c|c|c|c|c|c|}
\hline & \multirow[b]{3}{*}{ CSM Attribute } & \multicolumn{9}{|c|}{ SSE/SSE Intention/sunscreen use intention } & \multirow[t]{3}{*}{ Sig } \\
\hline & & \multicolumn{3}{|l|}{ Yes $^{1}$} & \multicolumn{3}{|c|}{ Don't know } & \multicolumn{3}{|l|}{ No } & \\
\hline & & $\mathrm{n}$ & Mean & SD & $n$ & Mean & SD & $n$ & Mean & SD & \\
\hline \multirow[t]{4}{*}{ Skin Self Examination (SSE) } & $\begin{array}{l}\text { Identity: How much skin cancer } \\
\text { would affect your life? }\end{array}$ & 38 & 7.66 & 2.122 & 561 & 8.13 & 1.888 & 24 & 8.13 & 2.071 & 0.375 \\
\hline & $\begin{array}{l}\text { Control: How much control you feel } \\
\text { you have to prevent skin cancer? }\end{array}$ & 38 & 6.39 & 2.047 & 562 & 5.65 & 2.256 & 24 & 5.13 & 2.659 & 0.128 \\
\hline & $\begin{array}{l}\text { Timeline: Given your age, how } \\
\text { relevant to conduct SSE? }\end{array}$ & 38 & 6.42 & 2.332 & 557 & 5.13 & 2.241 & 24 & 4.92 & 2.749 & $0.008^{* *}$ \\
\hline & $\begin{array}{l}\text { Consequences: How painful the } \\
\text { effects of skin cancer would be? }\end{array}$ & 38 & 7.24 & 2.307 & 557 & 7.02 & 2.014 & 24 & 6.75 & 2.625 & 0.707 \\
\hline \multirow[t]{4}{*}{ SSE Intention } & $\begin{array}{l}\text { Identity: How much skin cancer } \\
\text { would affect your life? }\end{array}$ & 96 & 8.56 & 1.514 & 261 & 8.12 & 1.759 & 265 & 7.93 & 2.104 & 0.078 \\
\hline & $\begin{array}{l}\text { Control: How much control you feel } \\
\text { you have to prevent skin cancer? }\end{array}$ & 96 & 6.00 & 2.088 & 261 & 5.98 & 2.057 & 265 & 5.24 & 2.433 & $<0.001^{* * *}$ \\
\hline & $\begin{array}{l}\text { Timeline: Given your age, how } \\
\text { relevant to conduct SSE? }\end{array}$ & 96 & 6.10 & 2.174 & 258 & 5.56 & 2.027 & 263 & 4.53 & 2.373 & $<0.001^{* * *}$ \\
\hline & $\begin{array}{l}\text { Consequences: How painful the } \\
\text { effects of skin cancer would be? }\end{array}$ & 95 & 7.40 & 1.991 & 260 & 7.04 & 2.000 & 263 & 6.89 & 2.125 & 0.101 \\
\hline \multirow[t]{4}{*}{ Sunscreen Intention } & $\begin{array}{l}\text { Identity: How much skin cancer } \\
\text { would affect your life? }\end{array}$ & 363 & 8.33 & 1.749 & 156 & 7.81 & 1.947 & 100 & 7.67 & 2.265 & $<0.001^{* * *}$ \\
\hline & $\begin{array}{l}\text { Control: How much control you feel } \\
\text { you have to prevent skin cancer? }\end{array}$ & 363 & 5.80 & 2.129 & 157 & 5.60 & 2.287 & 100 & 5.36 & 2.607 & 0.190 \\
\hline & $\begin{array}{l}\text { Timeline: Given your age, how } \\
\text { relevant to conduct SSE? }\end{array}$ & 359 & 5.29 & 2.214 & 156 & 5.19 & 2.246 & 100 & 4.95 & 2.560 & 0.412 \\
\hline & $\begin{array}{l}\text { Consequences: How painful the } \\
\text { effects of skin cancer would be? }\end{array}$ & 362 & 7.26 & 1.916 & 154 & 6.79 & 2.016 & 100 & 6.53 & 2.460 & $0.002^{* *}$ \\
\hline
\end{tabular}


Table 5 Associations between CSM Causes (Age, Sex, Hereditary Factors) and SSE, intention and sunscreen intention at baseline

\begin{tabular}{|c|c|c|c|c|c|c|c|}
\hline & \multicolumn{2}{|l|}{ Yes } & \multicolumn{2}{|c|}{ Don't know } & \multicolumn{2}{|l|}{ No } & \multirow[t]{2}{*}{ Sig } \\
\hline & $\%$ & $n$ & $\%$ & $(n)$ & $\%$ & (n) & \\
\hline Skin Self Examination (SSE) & 9.8 & 19 & 5.2 & 10 & 85.1 & 165 & 0.006 \\
\hline SSE Intention & 20.1 & 39 & 41.2 & 80 & 38.7 & 75 & 0.079 \\
\hline Sunscreen Intention & 61.7 & 119 & 25.9 & 50 & 12.4 & 24 & 0.187 \\
\hline
\end{tabular}

behaviour for each of the four aspects of planning: When $(p<0.001)$; Where $(p<0.001)$; How $(p=0.001)$; Coping $(p=0.001)$ (Table 3$)$. For example, 10.5\% $(n=4)$ of adolescents who had conducted SSE in the past month had made a plan when to conduct SSE compared to $1.8 \%$ $(n=10)$ who had not conducted SSE (Table 3).

There were statistically significant associations between SSE behaviour and CSM dimensions timeline and cause. Adolescents who had conducted SSE in the past month believed more strongly than those who had not conducted SSE in the past month that it was relevant to conduct SSE at their age (mean 6.42 vs. $4.92 ; p=0.008$ ) (Table 4). 9.8\% $(n=19)$ of adolescents who did SSE in the previous month associated skin cancer causes with age, sex and constitutional factors and $4.3 \%(n=17)$ who reported SSE in the previous month associated skin cancer causes with other factors (i.e. individual lifestyle factors or general environmental conditions) $(p=0.006)$ (Table 5).

There were statistically significant associations between SSE intention and CSM dimensions timeline and control. Adolescents who intended to conduct SSE on a regular basis believed more strongly than those who did not intend to conduct SSE that they had control to prevent skin cancer (mean 6.00 vs. $5.24 ; p<0.001$ ) and that it was relevant to conduct SSE at their age (mean 6.10 vs. $4.53 ; p<0.001)$. No significant differences were observed for the CSM dimensions identity, consequences (Table 4) and causes (Table 5).

\section{Indicative intervention outcomes Sunscreen use intention and planning}

Comparisons between baseline and follow-up scores show that there were statistically significant beneficial changes in sunscreen use intention and sunscreen use planning behaviour for adolescents in the intervention

Table 6 Skin Self Examination (SSE) behaviour at baseline by gender

\begin{tabular}{|c|c|c|c|c|c|c|c|}
\hline & \multicolumn{2}{|c|}{ Total $(n=625)$} & \multicolumn{2}{|c|}{ Male $(n=342)$} & \multicolumn{2}{|c|}{ Female $(n=283)$} & \multirow[t]{2}{*}{ Sig. } \\
\hline & $\%$ & $(n)$ & $\%$ & $(n)$ & $\%$ & $(n)$ & \\
\hline Yes & 6.1 & (38) & 5.6 & (19) & 6.7 & (19) & 0.42 \\
\hline No & 90.1 & (563) & 89.8 & (307) & 90.5 & (256) & \\
\hline Don't Know & 3.8 & (24) & 4.7 & (16) & 2.8 & (8) & \\
\hline
\end{tabular}

group but not for adolescents in the control group (Table 7). For example, intention to use a high factor sunscreen significantly increased in the intervention group (mean 3.67 to $3.88, p<0.001$ ) but decreased in the control group (3.61 to 3.37, $p=0.015$ ) (Table 7). However, after adjusting for age there were no statistically significant differences in sunscreen use intention and planning behaviour between baseline and follow-up in either the control or intervention groups (Table 7).

\section{SSE behaviour, intention and planning}

Comparisons between baseline and follow-up scores show that proportionately more adolescents in the intervention group changed their SSE behaviour for the better compared with adolescents in the control group (5.6 to $32.6 \%, p<0.001$ vs. 8.7 to $12.5 \%, p=0.337$ ) (Table 7 ).

There was a statistically significant beneficial change in intentions to regularly conduct SSE in the intervention group (mean 2.62 to $3.04, p<0.001$ ) between baseline and follow-up whereas there was a statistically significant detrimental change in the control group (mean 2.71 to $2.49, p=0.035$ ) (Table 7 ). However, after adjusting for age no statistically significant differences in SSE intention between baseline and follow-up were observed in either the intervention $(p=0.051)$ or control $(p=0.035)$ groups (Table 7).

Comparisons between baseline and follow-up scores show that there was a significant beneficial change in SSE planning behaviour in the intervention group whereas there were no significant changes in the control group for planning when, where and how to conduct SSE (Table 6). For example, there was a significant beneficial change in planning when to conduct SSE in the intervention group (mean 1.48 to $2.21, p<0.001$ ) and no statistically significant change in the control group (mean 1.47 to $1.49, p=0.3$ ) (Table 6). There was a statistically significant beneficial change in coping planning in the intervention group (mean 1.65 to 2.37, $p<0.001$ ) and in the control group (mean 1.48 to $1.76, p=0.017$ ) (Table 7). After adjusting for age no statistically significant changes were observed for any of the four measures of SSE planning in the control group, and the only measure that remained statistically significant in the intervention group was planning how to conduct SSE $(p=0.022)$ (Table 7).

\section{Talk about skin cancer}

At baseline, 9.2\% $(n=57)$ of adolescents reported that they had talked to someone in the past month about skin cancer (Table 1). No statistically significant gender differences were observed (Table 1). The number of adolescents talking about skin cancer in the last month that received the intervention significantly increased after the intervention (9.2 to $53.5 \%, p<0.001$ ); no statistically 
Table 7 Change in outcome measures between baseline and follow-up

\begin{tabular}{|c|c|c|c|c|c|c|c|c|c|c|}
\hline \multirow[b]{3}{*}{ Outcome Measures } & \multicolumn{5}{|l|}{ Control } & \multicolumn{5}{|l|}{ Intervention } \\
\hline & \multirow{2}{*}{$\begin{array}{l}\text { Baseline } \\
\text { Mean (SD) }\end{array}$} & \multicolumn{2}{|l|}{ Follow-up } & \multirow{2}{*}{$\begin{array}{l}\text { Unadjusted } \\
\text { Sig }\end{array}$} & \multirow{2}{*}{$\begin{array}{l}\text { Adjusted } \\
\text { Sig }\end{array}$} & \multirow{2}{*}{$\begin{array}{l}\text { Baseline } \\
\text { Mean (SD) }\end{array}$} & \multicolumn{2}{|l|}{ Follow-up } & \multirow{2}{*}{$\begin{array}{l}\text { Unadjusted } \\
\text { Sig }\end{array}$} & \multirow{2}{*}{$\begin{array}{l}\text { Adjusted } \\
\text { Sig }\end{array}$} \\
\hline & & Mean (SD) & $\mathrm{n}$ & & & & Mean (SD) & $\mathrm{n}$ & & \\
\hline \multicolumn{11}{|c|}{ Sunscreen Use Intention and Planning Behaviour } \\
\hline Intention to use sunscreen & $3.61(1.203)$ & $3.37(1.341)$ & 79 & $0.015^{*}$ & 0.388 & $3.67(1.177)$ & $3.88(1.099)$ & 360 & $<0.001^{* * *}$ & 0.186 \\
\hline $\begin{array}{l}\text { Plan WHAT sunscreen intend } \\
\text { to use }\end{array}$ & $2.47(1.440)$ & $2.44(1.366)$ & 79 & 0.443 & 0.773 & $2.64(1.353)$ & $3.33(1.268)$ & 369 & $<0.001^{* * *}$ & 0.261 \\
\hline Plan WHEN to use sunscreen & $2.52(1.376)$ & $2.44(1.366)$ & 79 & 0.533 & 0.803 & $3.01(1.378)$ & $3.33(1.268)$ & 369 & $<0.001^{* * *}$ & 0.817 \\
\hline Plan WHERE to get it & $2.43(1.420)$ & $2.29(1.360)$ & 79 & 0.237 & 0.965 & $2.81(1.479)$ & $3.17(1.358)$ & 369 & $<0.001^{* * *}$ & 0.779 \\
\hline Plan HOW to get it & $2.27(1.288)$ & $2.10(1.257)$ & 79 & 0.198 & 0.952 & $2.52(1.365)$ & $2.93(1.259)$ & 368 & $<0.001^{* * *}$ & 0.196 \\
\hline COPING Plan & $2.11(1.368)$ & $2.04(1.203)$ & 79 & 0.513 & 0.479 & $2.32(1.309)$ & $2.91(1.337)$ & 366 & $<0.001^{* * *}$ & 0.915 \\
\hline \multicolumn{11}{|c|}{ Skin Self Examination Intention and Planning Behaviour } \\
\hline $\begin{array}{l}\text { Intention to examine skin for } \\
\text { possible signs of skin cancer } \\
\text { on a regular basis }\end{array}$ & $2.71(0.865)$ & $2.49(0.932)$ & 79 & $0.035^{*}$ & 0.456 & $2.62(0.976)$ & 3.040 .978 & 375 & $<0.001^{* * *}$ & 0.051 \\
\hline $\begin{array}{l}\text { I have made a detailed plan } \\
\text { regarding WHEN }\end{array}$ & $1.47(0.875)$ & $1.49(0.799)$ & 79 & 0.300 & 0.125 & $1.48(0.842)$ & $2.21(1.103)$ & 376 & $<0.001^{* * *}$ & 0.718 \\
\hline $\begin{array}{l}\text { I have made a detailed plan } \\
\text { regarding WHERE }\end{array}$ & $1.56(0.920)$ & $1.56(0.877)$ & 78 & 0.991 & 0.569 & $1.61(0.945)$ & $2.62(1.221)$ & 374 & $<0.001^{* * *}$ & 0.192 \\
\hline $\begin{array}{l}\text { I have made a detailed plan } \\
\text { regarding HOW }\end{array}$ & $1.55(0.935)$ & $1.62(0.901)$ & 78 & 0.744 & 0.996 & $1.55(0.858)$ & $2.72(1.213)$ & 374 & $<0.001^{* * *}$ & $0.022^{*}$ \\
\hline $\begin{array}{l}\text { I have made a detailed plan } \\
\text { for COPING }\end{array}$ & $1.48(0.830)$ & $1.76(0.950)$ & 79 & $0.017^{*}$ & 0.672 & $1.65(0.915)$ & $2.37(1.166)$ & 372 & $<0.001^{* * *}$ & 0.426 \\
\hline \multicolumn{11}{|l|}{ Skin cancer risk representations } \\
\hline $\begin{array}{l}\text { Identity: How much skin } \\
\text { cancer would affect your life }\end{array}$ & $7.70(2.084)$ & $7.71(2.316)$ & 77 & 0.729 & 0.888 & $8.22(1.806)$ & $8.26(1.943)$ & 375 & 0.215 & 0.474 \\
\hline $\begin{array}{l}\text { Control: How much control } \\
\text { you feel you have to prevent } \\
\text { skin cancer }\end{array}$ & $5.29(2.251)$ & $5.05(2.197)$ & 78 & 0.834 & 0.990 & $5.90(2.254)$ & $6.62(1.893)$ & 376 & $<0.001^{* * *}$ & $0.029^{*}$ \\
\hline $\begin{array}{l}\text { Timeline: Given you age, how } \\
\text { relevant to conduct SSE }\end{array}$ & $4.81(2.391)$ & $4.59(2.265)$ & 78 & 0.767 & 0.104 & $5.23(2.308)$ & $7.14(2.068)$ & 372 & $<0.001^{* * *}$ & 0.873 \\
\hline \multirow{2}{*}{$\begin{array}{l}\text { Consequences: How painful } \\
\text { the effects of skin cancer } \\
\text { would be }\end{array}$} & $6.74(2.002)$ & $6.21(2.223)$ & 76 & 0.053 & 0.869 & $7.05(2.036)$ & $6.96(2.200)$ & 369 & 0.524 & $<0.001^{* * *}$ \\
\hline & $\%(n)$ & $\%(n)$ & & & & $\%(n)$ & $\%(n)$ & & & \\
\hline \multicolumn{11}{|c|}{ Skin Self Examination in past month } \\
\hline (\% Yes) & $8.7(8)$ & $12.5(13)$ & & $0.337\left(^{+}\right)$ & $0.599\left(^{+}\right)$ & $5.6(30)$ & $32.6(143)$ & & $<0.001^{* * *}\left({ }^{+}\right)$ & $<0.001^{* * *}\left({ }^{+}\right)$ \\
\hline$(\% \mathrm{No})$ & $85.9(79)$ & $82.7(86)$ & & & & $90.8(486)$ & $65.1(286)$ & & & \\
\hline (\% Don't know) & $5.4(5)$ & $4.8(5)$ & & & & $3.6(19)$ & $2.3(10)$ & & & \\
\hline \multicolumn{11}{|c|}{ Talk about skin cancer in the past month } \\
\hline (\% Yes) & $8.7(8)$ & $14.6(15)$ & & $0.866\left(^{+}\right)$ & $0.888\left(^{+}\right)$ & $9.2(49)$ & $53.5(234)$ & & $<0.001^{* *\left(^{+}\right)}$ & $<0.001^{* *\left(^{+}\right)}$ \\
\hline$(\% \mathrm{No})$ & $91.3(84)$ & $85.4(88)$ & & & & $90.8(481)$ & $46.5(203)$ & & & \\
\hline
\end{tabular}

Note: ${ }^{*} p<0.05,{ }^{* * *} p<0.001$

(+) $p$-values refer to the comparison between control and intervention for baseline and follow-up separately. Logistic regression model was applied to take into account confounder 'Age'

significant increase was observed in the control school (8.7 to $14.6 \%, p=0.866$ ) (Table 7 ).

\section{Skin cancer risk representations}

Comparisons between baseline and follow-up scores show that there were no statistically significant changes in CSM dimensions in the control group (Table 7). In the intervention group, before adjusting for age, there were statistically significant changes in CSM dimensions control and timeline; adolescents in the intervention group believed more strongly that they had control to prevent skin cancer at follow-up than they did at 
baseline (mean 5.90 versus $6.62, \mathrm{p}<0.001$ ) and believed more strongly that it was relevant to conduct SSE at their age $(7.14$ versus $5.23, \mathrm{p}<0.001)$ (Table 7). After adjusting for age, changes in the CSM dimension control remained statistically significant $(p=0.029)$ and change in the consequences measure was statistically significant $(p<0.001)$ (Table 7).

\section{Discussion}

A key purpose of conducting this feasibility study was to evaluate trial parameters. The response rate from schools was low (only 5 out of 37 schools that were approached agreed to participate) and reflects busy curricula timetables at the time of year when students aged 15-16 years in the UK are studying for exams. Our cancer awareness intervention trials conducted with younger adolescents who are not in an examination period have experienced a much higher school response rate [62]. Thus, the lead up to examination revision and examinations should be avoided in future research with this age group. Nonetheless, no parent/carer opted their child from the study and no student declined to participate, suggesting that it was an acceptable intervention. The proportion of students on the school register completing baseline and follow-up questionnaires was 50.5\%, which we believe could be improved if the study was conducted outside of the examination revision period. The proportion of students in intervention schools receiving the intervention was high (81\%) but only a third of students completed the home-based assignment. Our findings suggest that the number of students completing the home-based assignment could be improved if adolescents saw the relevance of SSE (a key part of the assignment) for their age group.

The onset of multiple risk behaviours, including excessive sun exposure, cluster in adolescence and there is a recognised need to determine the effectiveness of interventions to address this problem [23]. Hence, a further purpose of the feasibility study was to determine if the intervention worked as intended. The study shows that at baseline, $58.5 \%$ of adolescents intended to use a high factor sunscreen if they were going out in the sun and that female adolescents had a greater intention to use sunscreen than males. This finding is similar to other studies conducted in the UK $[16,63]$ and elsewhere $[17,64-66]$. The number of adolescents who reported that they had conducted SSE was low (6.1\%) and only $15.3 \%$ intended to examine their skin on a regular basis. This is similar to a figure of $4 \%$ of 16 to 25 year olds reported by a survey conducted in Northern Ireland [40]. We found females had a greater intention to conduct SSE on a regular basis than males. Other studies have also found that SSE is associated with being female [35]. Taken together, this body of work provides convincing evidence of the need for interventions to increase sunscreen use and SSE in this age group. The feasibility study was not designed to definitely measure effectiveness but rather to give an indication that the intervention worked as intended. As hypothesised, the study suggests that the intervention will facilitate beneficial changes in adolescent sunscreen use intention and SSE behaviour and intention, and adds to the body of work reporting the beneficial effects of psycho-educational interventions on sun protection behaviours in adolescents $[48,66-70]$. There is, however, only a very limited body of work about SSE in adolescents to which we can compare our findings. A study of Turkish teenagers (mean age 13 years) found significant increases in intentions to conduct SSE following an educational intervention [71]; however, the study did not include a control group. The feasibility study highlights that the use of personal stories is an important method for delivering crucial health messages. In this intervention, personal stories presented by video ('Dear 16 year old me') or in-person (young adult cancer survivor) were remembered by adolescents 8 weeks after the intervention was delivered in schools. Our qualitative findings also suggest that a skin cancer presentation delivered in schools will provide further potential teachable moments between parents/carers and their child about sun protection.

Understanding the pathways through which behaviour change occurs is important during feasibility work; a key purpose of this feasibility study was to determine if the above observed intervention effects on sunscreen use intention and SSE behaviour/intention occurred through hypothesised pathways of theoretical mediation. To evaluate this, we first examined associations between planning, illness perceptions and sunscreen use and SSE at baseline and second, we measured changes in planning and illness perceptions from baseline to follow-up. As hypothesised, at baseline, we found significant associations between planning and sunscreen use intention, SSE behaviour and SSE intention. Other studies have also reported associations between planning and sunscreen use in adolescents [18] and adults [72] and between planning and SSE [43]. A mobile text messaging-delivered behavioural intervention in a population aged 18 to 42 years found that those who had made plans to check their skin for early signs of skin cancer were more likely to conduct SSE [43]. There is therefore a growing body of empirical evidence to corroborate theoretical models suggesting that behavioural intentions are more likely to be translated into action when people generate specific plans $[45,56]$ and points to the inclusion of planning activities in interventions to increase sunscreen use and SSE in adolescents. We also, as hypothesised, observed significant associations at baseline between illness perceptions (including risk perception) and sunscreen use intention and SSE behaviour/ 
intention. Hence, our study findings are consistent with other research showing associations between risk perceptions and sunscreen use in adolescents [18, 21, 48, 49, 73] and between the CSM dimension timeline and SSE in young adults [54] and are consistent with the thesis that risk perceptions influence behaviour [53]. We can only speculate reasons why we did not consistently find associations between all five CSM dimensions and sunscreen and SSE behaviour/intention. It could be that some illness perceptions are more influential than others and vary by behaviours. However, a more likely explanation is that our findings are an artefact of study design; perhaps it is not surprising that we did not observe an association between relevance beliefs (i.e. measured in this study by the CSM dimension timeline) and sunscreen use intention because we only included one item and that item related specifically to adolescents' perceived relevance of SSE during adolescence and we did not measure their perceived relevance of using sunscreen during adolescence. Importantly, we only operationalised illness perceptions using CSM dimensions of illness representation. It has been suggested that different risk perception operationalisations explain the inconsistent findings in literature regarding the relationship between risk perceptions and cancer-related behaviours [74]. Hence, future studies should consider operationalising illness perceptions using a range of behaviour change theories and theoretical constructs.

\section{Limitations}

Our study provides new evidence regarding interventions that simultaneously address sunscreen use to prevent skin cancer and SSE to improve early detection that was previously lacking internationally. However, several limitations of the study must be noted. First, the sample consists of a small number of mainly white British adolescents selected from only five schools and so may not generalise to populations with different cultural backgrounds. Second, the study was conducted during January to March when it is cold in the UK and when the population is less likely to think about use of sun protection. Whether the findings would be similar during the summer months is unclear but given that we found the intervention appeared to influence sunscreen use and SSE when the population is possibly less receptive to sun safe messaging we are confident that this would be the case. Third, the study relied on self-report and is therefore prone to social desirability reporting biases. In this study, we did not measure actual sunscreen use (we only measured intention) nor did we examine associations between sunscreen use and sunburn incidence. If sunscreen use does not lead to a reduction in sunburn then even if an intervention were to improve sunscreen use it would not necessarily improve health outcomes unless sunburn declined as a consequence of increasing sunscreen use. Further research should therefore consider objective measurement of sunscreen use and sunburn incidence. Similarly, any study that relies on self-reported SSE is subject to recall bias, and may lead to the overestimation of SSE behaviour. Increasing use of mobile photo-documentation means that future studies may be in a position to include objective measurement of SSE $[75,76]$. We did not ask participants whether they examined their whole body during SSE, only arms and legs, and how SSE is measured can yield different results [35]. Fourth, as mentioned previously, risk perception was only operationalised using CSM and other behaviour theories could strengthen the intervention. This is because there are other social cognitions that may influence behaviour and should therefore be considered in future studies. For example, outcome expectancy (a belief about the likelihood of the behaviour leading to a specific outcome) has been associated with sun protection and SSE [43] and appearance motives have been associated with sunscreen use intention in adolescents [67]. Fifth, while promising, our study suggests that this brief intervention on its own has limitations. Our qualitative findings suggest that adolescents may defer using sunscreen because they do not like its texture or smell. Whether the intervention messages about sun protection are sufficiently powerful to overcome these barriers in the long-term is unclear from this study. Adolescents also questioned the relevancy of SSE during adolescence. While they understood and retained the message that sunburn in childhood and adolescence increases their chances of skin cancer, they also understood and retained the message that the negative effects on health are likely only to be apparent many years later. Making SSE habitual by beginning in adolescence may therefore prove challenging. We may need to develop 'Do you know your skin?' by increasing intervention intensity, the relevance of SSE during adolescence, and consider combining it with other interventions (e.g. increasing availability of adolescent-friendly sunscreen) as part of a larger programme of effort to promote sunscreen use and SSE.

\section{Conclusion}

This study suggests that it is feasible to simultaneously promote sun safe behaviours and skin self-examination using a theory-based psycho-educational intervention but further research is required to improve study uptake, intervention adherence and effectiveness.

\section{Additional files}

Additional file 1: CONSORT flowchart for trials. Number of participants screened, enrolled, allocated to intervention or control arms, and follow up and assessment rates. (DOCX 64 kb)

Additional file 2: Qualitative data from the focus groups. Table with thematic headings and related quotations from participants. (DOCX $102 \mathrm{~kb}$ ) 


\section{Abbreviations}

CSM: Common-sense model of illness representation; SSE: Skin self-examination

\section{Acknowledgements}

We thank Sheena Dryden, skin cancer specialist nurse and Jack Brodie, young adult skin cancer survivor who delivered the intervention. We also thank students and teachers who participated in the study.

\section{Funding}

This work was supported by the UK charity Melanoma Focus

\section{Availability of data and materials}

The datasets used and/or analysed during the current study are available from the corresponding author on reasonable request.

\section{Authors' contributions}

$\mathrm{GH}, \mathrm{SD}, \mathrm{RK}, \mathrm{RN}$, designed the study; GH led the study and prepared first draft of the manuscript; GH, ZW recruited schools, collected data and conducted thematic analysis; VM conducted statistical analyses; all authors reviewed and agreed the final manuscript.

\section{Ethics approval and consent to participate}

The study was approved at University of Stirling Research and Ethics committee (SREC 15/16 - Paper No.66 - Version 2). The consent procedure was as follows: Once a school had consented to participate, the named parent/carer on the school register was sent a study information pack, which included a form to be returned to the school if they wished to opt their child out of the study. The parent/carer was given the opportunity to contact the research team to discuss the study by telephone or email. Students who were not opted out by a parent/carer were given their study information sheet and consent form in the classroom. Students who had been opted out of the study were given education assignments to do while their classmates completed the questionnaires.

\section{Competing interests}

The authors have no competing interests.

\section{Publisher's Note}

Springer Nature remains neutral with regard to jurisdictional claims in published maps and institutional affiliations.

\section{Author details}

${ }^{1}$ School of Health, Social Care and Life Sciences, Centre for Health Sciences, University of the Highlands and Islands (UHI), Old Perth Road, Inverness IV2 $3 \mathrm{JH}$, Scotland. ${ }^{2}$ School of Health and Social Care, Edinburgh Napier University, Sighthill Court, Edinburgh EH11 4BN, UK. ${ }^{3}$ Academic Unit of Primary Care, Institute of Health Sciences, University of Leeds, Worsley Building, Leeds LS2 9NL, UK. ${ }^{4}$ Department of Management, Faculty of Economics, Management and Accountancy, University of Malta, Humanities B (FEMA), Msida, MSD 2080, Malta. ${ }^{5}$ Division of Psychology, Faculty of Natural Sciences, University of Stirling, FK10 4LA Stirling, Scotland.

Received: 13 November 2017 Accepted: 16 May 2018

Published online: 29 May 2018

\section{References}

1. de Vries E, Arnold M, Altsitsiadis E, Trakatelli M, Hinrichs B, Stockfleth E, Coebergh J, Group E. Potential impact of interventions resulting in reduced exposure to ultraviolet (UV) radiation (UVA and UVB) on skin cancer incidence in four European countries, 2010-2050. Br J Dermatol. 2012;167(Suppl 2):53-62.

2. Skin cancer incidence statistics [http://www.cancerresearchuk.org/healthprofessional/cancer-statistics/statistics-by-cancer-type/skin-cancer].

3. Parkin DM, Mesher D, Sasieni P. 13. Cancers attributable to solar (ultraviolet) radiation exposure in the UK in 2010. Br J Cancer. 2011;105(Suppl 2):S66-9.

4. Green A, Battistutta D. Incidence and determinants of skin cancer in a highrisk Australian population. Int J Cancer. 1990;46(3):356-61.

5. Kricker A, Armstrong BK, English DR, Heenan PJ. A dose-response curve for sun exposure and basal cell carcinoma. Int J Cancer. 1995;60(4):482-8.

6. Elwood JM, Jopson J. Melanoma and sun exposure: an overview of published studies. Int J Cancer. 1997;73(2):198-203.
7. Alston RD, Rowan S, Eden TOB, Moran A, Birch JM. Cancer incidence patterns by region and socioeconomic deprivation in teenagers and young adults in England. Brit J Cancer. 2007;96(11):1760-6.

8. Mitsis DKL, Groman A, Beaupin LM, Salerno KE, Francescutti V, Skitzki J J, Kane JM, Khushalani NI. Trends in demographics, incidence, and survival in children, adolescents and young adults (AYA) with melanoma: A Surveillance, Epidemiology and End Results (SEER) population-based analysis. J Clin Oncol. 2015;33(15):9058.

9. Deady S, Sharp L, Comber H. Increasing skin cancer incidence in young, affluent, urban populations: a challenge for prevention. Brit J Dermatol. 2014;171(2):324-31.

10. Youl P, Aitken J, Hayward N, Hogg D, Liu L, Lassam N, Martin N, Green A: Melanoma in adolescents: a case-control study of risk factors in Queensland, Australia Int J Cancer 2002, 98(1):92-98.

11. Oliveria SA, Saraiya M, Geller AC, Heneghan MK, Jorgensen C. Sun exposure and risk of melanoma. Arch Dis Child. 2006;91(2):131-8.

12. Iannacone MR, Wang W, Stockwell HG, O'Rourke K, Giuliano AR, Sondak VK, Messina JL, Roetzheim RG, Cherpelis BS, Fenske NA, et al. Patterns and timing of sunlight exposure and risk of basal cell and squamous cell carcinomas of the skin-a case-control study. BMC Cancer. 2012;12:417.

13. Vranova J, Arenbergerova M, Arenberger P, Stanek J, Vrana A, Zivcak J, Rosina J. Incidence of cutaneous malignant melanoma in the Czech Republic: the risks of sun exposure for adolescents. Neoplasma. 2012;59(3):316-25

14. Wu SW, Han JL, Laden F, Qureshi AA. Long-term ultraviolet flux, other potential risk factors, and skin Cancer risk: a cohort study. Cancer Epidem Biomar. 2014;23(6):1080-9.

15. Sanchez G, Nova J, Rodriguez-Hernandez AE, Medina RD, SolorzanoRestrepo C, Gonzalez J, Olmos M, Godfrey K, Arevalo-Rodriguez I. Sun protection for preventing basal cell and squamous cell skin cancers. Cochrane Db Syst Rev. 2016;7. Art. No.: CD011161. https://doi.org/10.1002/ 14651858.CD011161.pub2.

16. Kyle RG, Macmillan I, Forbat L, Neal RD, O'Carroll RE, Haw S, Hubbard G. Scottish adolescents' sun-related behaviours, tanning attitudes and associations with skin cancer awareness: a cross-sectional study. BMJ Open. 2014:4(5):e005137.

17. Buendia Eisman A, Arias Santiago S, Moreno-Gimenez JC, Cabrera-Leon A, Prieto L, Castillejo I, Conejo-Mir J. An internet-based programme to promote adequate UV exposure behaviour in adolescents in Spain. J Eur Acad Dermatol Venereol. 2013;27(4):442-53.

18. de Vries H, Mesters I, van't Riet J, Willems K, Reubsaet A. Motives of Belgian adolescents for using sunscreen: the role of action plans. Cancer Epidem Biomar. 2006;15(7):1360-6.

19. Davis KJ, Cokkinides VE, Weinstock MA, O'Connell MC, Wingo PA. Summer sunburn and sun exposure among US youths ages 11 to 18: national prevalence and associated factors. Pediatrics. 2002;110(1 Pt 1):27-35.

20. Lupton D, Gaffney D. Discourses and practices related to suntanning and solar protection among young Australians. Health Educ Res. 1996;11(2):147-59.

21. Wichstrom L. Predictors of Norwegian adolescents' sunbathing and use of sunscreen. Health Psychol. 1994;13(5):412-20.

22. NICE: Sunlight exposure: Risks and benefits NG34. In.; 2016.

23. Kipping RR, Campbell RM, MacArthur GJ, Gunnell DJ, Hickman M. Multiple risk behaviour in adolescence. J Public Health (Oxf). 2012;34(Suppl 1):i1-2.

24. Degenhardt L, Chiu WT, Sampson N, Kessler RC, Anthony JC, Angermeyer M, Bruffaerts R, de Girolamo G, Gureje O, Huang Y, et al. Toward a global view of alcohol, tobacco, cannabis, and cocaine use: findings from the WHO world mental health surveys. PLoS Med. 2008;5(7):e141.

25. Viner R. Life stage: adolescence in: Our Children Deserve Better: Prevention Pays. Edn. Edited by chief medical officer. London: Department of Health; 2012.

26. Kendler KS, Myers J, Damaj MI, Chen X. Early smoking onset and risk for subsequent nicotine dependence: a monozygotic co-twin control study. Am J Psychiatry. 2013;170(4):408-13.

27. Lostritto K, Ferrucci LM, Cartmel B, Leffell DJ, Molinaro AM, Bale AE, Mayne ST. Lifetime history of indoor tanning in young people: a retrospective assessment of initiation, persistence, and correlates. BMC Public Health. 2012;12:118

28. Marks R. Skin cancer-childhood protection affords lifetime protection. Med J Aust. 1987; 147(10):475-6.

29. Skin cancer - Be clear on cancer [https://www.nhs.uk/be-clear-on-cancer/ symptoms/skin-cancer\#Kh628JolWz1xI2VU.97]. 
30. Step by Step Self-examination [https://www.skincancer.org/skin-cancerinformation/early-detection/step-by-step-self-examination].

31. Hamidi R, Peng D, Cockburn M. Efficacy of skin self-examination for the early detection of melanoma. Int J Dermatol. 2010;49(2):126-34.

32. Rutherford MJ, Ironmonger L, Ormiston-Smith N, Abel GA, Greenberg DC, Lyratzopoulos G, Lambert PC. Estimating the potential survival gains by eliminating socioeconomic and sex inequalities in stage at diagnosis of melanoma. Br J Cancer. 2015;112(Suppl 1):S116-23.

33. Neal RD, Tharmanathan $P$, France $B$, Din NU, Cotton $S$, Fallon-Ferguson J, Hamilton W, Hendry A, Hendry M, Lewis R, et al. Is increased time to diagnosis and treatment in symptomatic cancer associated with poorer outcomes? Systematic review. $\mathrm{Br} J$ Cancer. 2015;112(Suppl 1):S92-107.

34. Berwick M, Begg CB, Fine JA, Roush GC, Barnhill RL. Screening for cutaneous melanoma by skin self-examination. J Natl Cancer Inst. 1996;88(1):17-23.

35. Hamidi R, Cockburn MG, Peng DH. Prevalence and predictors of skin selfexamination: prospects for melanoma prevention and early detection. Int J Dermatol. 2008;47(10):993-1003.

36. Richard MA, Grob JJ, Avril MF, Delaunay M, Gouvernet J, Wolkenstein P, Souteyrand P, Dreno B, Bonerandi JJ, Dalac S, et al. Delays in diagnosis and melanoma prognosis (I): the role of patients. Int J Cancer. 2000;89(3):271-9.

37. Koh HK, Miller DR, Geller AC, Clapp RW, Mercer MB, Lew RA. Who discovers melanoma? Patterns from a population-based survey. J Am Acad Dermatol. 1992;26(6):914-9.

38. Gardner B, Lally P, Wardle J. Making health habitual: the psychology of 'habit-formation' and general practice. Br J Gen Pract. 2012;62(605):664-6.

39. Carli P, De Giorgi V, Palli D, Maurichi A, Mulas P, Orlandi C, Imberti G, Stanganelli I, Soma P, Dioguardi D, et al. Patterns of detection of superficial spreading and nodular-type melanoma: a multicenter Italian study. Dermatol Surg. 2004:30(11):1371-5. discussion 1375-1376

40. Gavin A, Boyle R, Donnelly D, Donnelly C, Gordon S, McElwee G, O'Hagan A. Trends in skin cancer knowledge, sun protection practices and behaviours in the Northern Ireland population. Eur J Pub Health. 2012;22(3):408-12

41. Hubbard G, Macmillan I, Canny A, Forbat L, Neal RD, O'Carroll RE, Haw S, Kyle RG. Cancer symptom awareness and barriers to medical help seeking in Scottish adolescents: a cross-sectional study. BMC Public Health. 2014:14:1117.

42. Walter FM, Birt L, Cavers D, Scott S, Emery J, Burrows N, Cavanagh G, MacKie R, Weller D, Campbell C. 'This isn't what mine looked like': a qualitative study of symptom appraisal and help seeking in people recently diagnosed with melanoma. BMJ Open. 2014;4(7):e005566.

43. Youl PH, Soyer HP, Baade PD, Marshall AL, Finch L, Janda M. Can skin cancer prevention and early detection be improved via mobile phone text messaging? A randomised, attention control trial. Prev Med. 2015;71:50-6.

44. Saraiya M, Glanz K, Briss PA, Nichols P, White C, Das D, Smith SJ, Tannor B, Hutchinson $A B$, Wilson $K M$, et al. Interventions to prevent skin cancer by reducing exposure to ultraviolet radiation: a systematic review. Am J Prev Med. 2004;27(5):422-66.

45. Schwarzer R. Modeling health behavior change: how to predict and modify the adoption and maintenance of health behaviors. Appl Psychol. 2008;57(1):1-29.

46. Floyd DL, Prentice-Dunn S, Rogers RW. A meta-analysis of research on protection motivation theory. J Appl Soc Psychol. 2000;30(2):407-29.

47. Sheeran P, Harris PR, Epton T. Does heightening risk appraisals change people's intentions and behavior? A meta-analysis of experimental studies. Psychol Bull. 2014;140(2):511-43.

48. Schuz N, Eid M. Beyond the usual suspects: target group- and behaviorspecific factors add to a theory-based sun protection intervention for teenagers. J Behav Med. 2013;36(5):508-19.

49. Lowe JB, Borland R, Stanton WR, Baade P, White V, Balanda KP. Sun-safe behaviour among secondary school students in Australia. Health Educ Res. 2000;15(3):271-81.

50. Robinson JK, Fisher SG, Turrisi RJ. Predictors of skin self-examination performance. Cancer. 2002;95(1):135-46.

51. Kasparian NA, Branstrom R, Chang YM, Affleck P, Aspinwall LG, Tibben A, Azizi E, Baron-Epel O, Battistuzzi L, Bruno W, et al. Skin examination behavior: the role of melanoma history, skin type, psychosocial factors, and region of residence in determining clinical and self-conducted skin examination. Arch Dermatol. 2012;148(10):1142-51.

52. Leventhal $\mathrm{H}$. Findings and theory in the study of fear communications. Adv Exp Soc Psychol. 1970;5:119-86.

53. Leventhal H, Phillips LA, Burns E. The common-sense model of selfregulation (CSM): a dynamic framework for understanding illness selfmanagement. J Behav Med. 2016;39(6):935-46.

54. Cameron LD. IIIness risk representations and motivations to engage in protective behavior: the case of skin cancer risk. Psychol Health. 2008;23(1):91-112

55. Miller SMD, M. A. C-SHIP: A cognitive-social health information processing approach to cancer. In: Krantz D, editor. Perspectives in Behavioral Medicine. NJ: Lawrence Erlbaum; 1998. p. 219-44.

56. Sniehotta FF, Nagy G, Scholz U, Schwarzer R. The role of action control in implementing intentions during the first weeks of behaviour change. Br J Soc Psychol. 2006;45(Pt 1):87-106.

57. Araujo-Soares $V$, Mclntyre T, Sniehotta FF. Predicting changes in physical activity among adolescents: the role of self-efficacy, intention, action planning and coping planning. Health Educ Res. 2009;24(1):128-39.

58. Moss-Morris R, Weinman J, Petrie K, Horne R, Cameron L, Buick D. The revised illness perception questionnaire (IPQ-R). Psychol Health. 2002;17(1):1-16.

59. Government Statistical Service: Ethnic Group. Harmonised Concepts and Questions for Social Data Sources: Primary Principles. London; 2015.

60. Whitehead M, Dahlgren G. What can be done about inequalities in health? Lancet. 1991;338(8774):1059-63.

61. Spencer LR, Ritchie J, O'Connor, W. Analysis: practices, principles and processes. In: Qualitative Research Practice: A Guide for Social Science Students and Researchers. edn. Edited by Ritchie JL. London: SAGE; 2003: 199-218.

62. Hubbard G, Stoddart I, Forbat L, Neal RD, O'Carroll RE, Haw S, Rauchhaus P, Kyle RG. School-based brief psycho-educational intervention to raise adolescent cancer awareness and address barriers to medical help-seeking about cancer: a cluster randomised controlled trial. Psychooncology. 2016;25(7):760-71.

63. Gould M, Farrar MD, Kift R, Berry JL, Mughal MZ, Bundy C, Vail A, Webb $A R$, Rhodes LE. Sunlight exposure and photoprotection behaviour of white Caucasian adolescents in the UK. J Eur Acad Dermatol. 2015;29(4):732-7.

64. Cokkinides V, Weinstock M, Glanz K, Albano J, Ward E, Thun M. Trends in sunburns, sun protection practices, and attitudes toward sun exposure protection and tanning among US adolescents, 1998-2004. Pediatrics. 2006;118(3):853-64.

65. Richards R, McGee R, Knight RG. Sunburn and sun protection among New Zealand adolescents over a summer weekend. Aust Nz J Publ Heal. 2001;25(4):352-4.

66. Dusza SW, Halpern AC, Satagopan JM, Oliveria SA, Weinstock MA, Scope A, Berwick M, Geller AC. Prospective study of sunburn and sun behavior patterns during adolescence. Pediatrics. 2012;129(2):309-17.

67. Olson AL, Gaffney CA, Starr P, Dietrich AJ. The impact of an appearancebased educational intervention on adolescent intention to use sunscreen. Health Educ Res. 2008;23(5):763-9.

68. Miljkovic S, Baljozovic D, Krajnovic D, Tasic L, Sbutega-Milosevic G. The impact of education on Adolescents' sun behavior: experiences from Serbia. Srp Ark Celok Lek. 2014;142(5-6):330-6.

69. Buller DB, Reynolds KD, Yaroch A, Cutter GR, Hines JM, Geno CR, Maloy JA, Brown M, Woodall WG, Grandpre J. Effects of the sunny days, healthy ways curriculum on students in grades 6 to 8. Am J Prev Med. 2006;30(1):13-22.

70. White KM, Hyde MK, O'Connor EL, Naumann L, Hawkes AL. Testing a beliefbased intervention encouraging sun-safety among adolescents in a high risk area. Prev Med. 2010;51(3-4):325-8.

71. Balyaci $O E$, Kostu N, Temel AB. Training program to raise consciousness among adolescents for protection against skin cancer through performance of skin self examination. Asian Pac J Cancer Prev. 2012;13(10):5011-7.

72. Craciun C, Schuz N, Lippke S, Schwarzer R. Enhancing planning strategies for sunscreen use at different stages of change. Health Educ Res. 2012;27(5):857-67 
73. Mermelstein RJ, Riesenberg LA. Changing knowledge and attitudes about skin cancer risk factors in adolescents. Health Psychol. 1992;11(6):371-6.

74. Janssen $E$, van Osch L, de Vries $H$, Lechner L. Measuring risk perceptions of skin cancer: reliability and validity of different operationalizations. Br J Health Psychol. 2011;16(Pt 1):92-112.

75. Janda M, Loescher LJ, Soyer HP. Enhanced skin self-examination: a novel approach to skin cancer monitoring and follow-up. JAMA Dermatol. 2013;149(2):231-6.

76. Vano-Galvan S, Paoli J, Rios-Buceta L, Jaen P. Skin self-examination using smartphone photography to improve the early diagnosis of melanoma. Actas Dermosifiliogr. 2015;106(1):75-7.

Ready to submit your research? Choose BMC and benefit from:

- fast, convenient online submission

- thorough peer review by experienced researchers in your field

- rapid publication on acceptance

- support for research data, including large and complex data types

- gold Open Access which fosters wider collaboration and increased citations

- maximum visibility for your research: over $100 \mathrm{M}$ website views per year 